\title{
Effect of electrolytic lesion of the dorsal raphe nucleus on water intake and sodium appetite
}

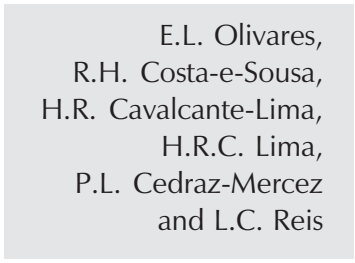

Departamento de Ciências Fisiológicas, Instituto de Biologia, Universidade Federal Rural do Rio de Janeiro, Seropédica, RJ, Brasil

\section{Correspondence}

L.C. Reis

Departamento de Ciências

Fisiológicas, IB, UFRuralRJ

Rodovia BR465, km 7

23890-000 Seropédica, RJ

Brasil

Fax: +55-21-2682-1763

E-mail: Icreis@ufrrj.br

Research supported by CAPES and Departamento de Ciências Fisiológicas, IB, UFRRJ.

Received February 19, 2003 Accepted August 7, 2003

\begin{abstract}
The present study determined the effect of an electrolytic lesion of the dorsal raphe nucleus (DRN) on water intake and sodium appetite. Male Wistar rats weighing 290-320 g with a lesion of the DRN (LDRN), performed two days before experiments and confirmed by histology at the end of the experiments, presented increased sensitivity to the dehydration induced by fluid deprivation. The cumulative water intake of L-DRN rats reached $23.3 \pm 1.9 \mathrm{ml}$ (a 79\% increase, $\mathrm{N}=9$ ) while sham-lesioned rats $(\mathrm{SL}-\mathrm{DRN})$ did not exceed $13.0 \pm 1.0 \mathrm{ml}$ $(\mathrm{N}=11, \mathrm{P}<0.0001)$ after $5 \mathrm{~h}$. The L-DRN rats treated with isoproterenol $\left(300 \mu \mathrm{g} \mathrm{kg}^{-1} \mathrm{ml}^{-1}, \mathrm{sc}\right)$ exhibited an increase in water intake that persisted throughout the experimental period (L-DRN, $15.7 \pm 1.47 \mathrm{ml}$, $\mathrm{N}=9$ vs SL-DRN, $9.3 \pm 1.8 \mathrm{ml}, \mathrm{N}=11, \mathrm{P}<0.05)$. The L-DRN rats also showed an increased spontaneous sodium appetite during the entire period of assessment. The intake of $0.3 \mathrm{M} \mathrm{NaCl}$ after 12, 24, 36 and 72 $\mathrm{h}$ by the L-DRN rats was always higher than $20.2 \pm 4.45 \mathrm{ml}(\mathrm{N}=10)$, while the intake by SL-DRN was always lower than $2.45 \pm 0.86 \mathrm{ml}$ $(\mathrm{N}=10, \mathrm{P}<0.00001)$. Sodium- and water-depleted L-DRN rats also exhibited an increased sodium appetite $(13.9 \pm 2.0 \mathrm{ml}, \mathrm{N}=11)$ compared to SL-DRN $(4.6 \pm 0.64 \mathrm{ml}, \mathrm{N}=11)$ after $120 \mathrm{~min}$ of observation $(\mathrm{P}<0.02)$. The sodium preference of L-DRN rats in both conditions was always higher than that of SL-DRN rats. These results suggest that electrolytic lesion of the DRN overcomes a tonic inhibi-

tory component of sodium appetite.
\end{abstract}

\section{Introduction}

Serotonergic neurons of the mesencephalic dorsal raphe nucleus (DRN), located in its medial portion, project to prosencephalic regions involved in hydroelectrolytic and cardiocirculatory homeostasis (1-4). Recipro-
Key words

- Sodium appetite

- Water intake

- Dorsal raphe nucleus

- Serotonergic system

- Electrolytic lesion

- Rats cal projections from structures of the terminal lamina constitute evidence that the monitoring of cardiocirculatory signals and changes in plasma tonicity and volume are sent to the DRN (4-7). Consistent with this, the angiotensinergic stimulation of the subfornical organ (SFO), which represents, in 
the short and long term, the changes in volume, pressure and sodium concentration in the extracellular fluid, evokes electrophysiological changes in the DRN (7). In this context, it has been shown that the microinjection of serotonergic agonists of the 5HT2A and $5 \mathrm{HT} 2 \mathrm{C}$ receptors into the SFO excites angiotensin II- (ANG II) sensitive neurons (8). In addition, structures of the lamina terminalis, including the SFO and those of the wall of the anteroventral region of the third ventricle (AV3V), the organum vasculosum laminae terminalis (OVLT), and the median preoptic nucleus (MnPO) constitute areas related to hydroelectrolytic and cardiovascular regulation (4,9-11). Relevant observations have shown that stimulation of the AV3V region by intracerebroventricular (icv) administration of serotonin, serotonin-releasing agents or $5 \mathrm{HT} 2 \mathrm{~A} / 2 \mathrm{C}$ agonists increases the urinary excretion of sodium $(12,13)$. All of these stimulation conditions under fluid deprivation, cholinergic or angiotensinergic stimulation of the $\mathrm{AV} 3 \mathrm{~V}$ region and central or systemic $B$ adrenergic stimulation also caused a decrease in water intake (14-16). These observations were later confirmed in part using different experimental paradigms in which the $5 \mathrm{HT} 2 \mathrm{~B} / 2 \mathrm{C}$ agonist, 1-3-chlorophenylpiperazine (mCPP), was administered by the icv route (17). The authors reported an inhibition of water intake after dipsogenic challenges induced by fluid deprivation, hypertonic saline overload or hypovolemia. Furthermore, it has been shown that basal c-Fos expression in serotoninergic neurons of the DRN was decreased after sodium depletion induced by peritoneal dialysis and was increased after spontaneous and induced sodium intake, suggesting that there is a tonic inhibition of sodium appetite by serotoninergic cells of this nucleus (18).

The observation that the recruitment of ascending serotonergic pathways by flow of information originated from prosencephalic structures implied hydroelectrolytic and cardiocirculatory regulation $(4,5,7)$. Taken together with the evidence that electrolytic lesions of the DRN reduce the basal or stimulated plasma levels of atrial natriuretic peptide (ANP), these data suggest that ascending pathways of the raphe integrate signals concerned with the volume of body fluid homeostasis through the control of renal water and electrolyte excretion, as well as of water intake (3).

No systematic studies involving the direct manipulation of the DRN and its implication in the expression of sodium appetite and water intake have been reported. There has been only a single report which demonstrated that electrolytic lesion of the DRN caused a chronic increase in water intake when only this fluid was offered (3).

The present study was designed to assess the effect of electrolytic lesion of the DRN on water intake in the experimental paradigms that involve an increase of extracellular fluid tonicity by fluid deprivation (osmotic thirst) and brain signaling induced by the systemic production of ANG II in dlisoproterenol-treated rats $(4,19-21)$. In addition, spontaneous sodium appetite was investigated in DRN-lesioned rats following a simultaneous offer of water and hypertonic saline for three consecutive days.

\section{Material and Methods}

\section{Animals}

Male Wistar rats weighing 290-320 g were maintained in a room with lights on from 7:00 to 19:00 h, at a controlled temperature of $25^{\circ} \mathrm{C}$ and with free access to Purina chow and water. Before brain stereotaxic surgery the rats were housed in metabolic cages for at least 5 days. Electrolytic lesions of the DRN were produced in rats anesthetized $i p$ with $2.5 \%$ tribromoethanol (Aldrich Chemical Company Inc., Milwaukee, WI, USA) and fixed in a stereotaxic frame. 


\section{Electrolytic lesions}

In order to perform the electrolytic lesions, stereotaxic coordinates were obtained according to the parameters defined in the atlas of Paxinos and Watson (22), using the anteroposterior (AP) coordinates $=7.6-7.8$ $\mathrm{mm}$, posterior to bregma, lateral $=0 \mathrm{~mm}$ and vertical $(\mathrm{V})=6.4-6.6 \mathrm{~mm}$, below the top of the skull.

The lesions were produced by passing an anodal current of $1 \mathrm{~mA}$ for $10 \mathrm{~s}$. Shamoperated rats were used as controls. At the end of the experiment the rats were sacrificed under deep anesthesia and transcardiac perfusion was performed with $10 \%$ formaldehyde. The location of the lesions was confirmed by histological examination of serial coronal sections $(10 \mu \mathrm{m})$ through the brainstem stained by the Nissl method. A prophylactic dose of 30,000 IU penicillin (Fort Dodge Saúde Animal Ltda., Campinas, SP, Brazil) was administered im to operated rats. Data for rats with lesions outside the dorsoventromedial region of the DRN were excluded from statistical analysis. All the experimental protocols and animal procedures were carried out in accordance with current Brazilian legislation.

\section{Statistical analysis}

Data were analyzed statistically by twoway analysis of variance with repeated measures, and the significance of differences between means was determined by the Newman-Keuls test. The difference between DRN-lesioned rats (L-DRN) and sham-lesioned rats (SL-DRN) was calculated in all experiments. The level of significance was set at 5\%. Data are reported as mean \pm SEM.

\section{Experimental procedures}

Water intake. Water intake was determined in rats submitted to $16 \mathrm{~h}$ of fluid deprivation and in rats treated with dl-isoproterenol (300 $\mu \mathrm{g} \mathrm{kg}^{-1} \mathrm{ml}^{-1}, s c$; Aldrich) for $5 \mathrm{~h}$ at hourly intervals. Under these conditions, thirst and water intake are related to an increased tonicity of the extracellular fluid and the systemic production of ANG II, respectively (4). In this set of experiments rats were used with an electrolytic lesion of the DRN (L-DRN, N = 9) or sham lesion (SL$\mathrm{DRN}, \mathrm{N}=11$ ) produced 2 days before treatment with isoproterenol or isotonic saline.

Spontaneous (basal) sodium appetite. In order to assess the sodium appetite, $0.3 \mathrm{M}$ $\mathrm{NaCl}$ was offered simultaneously with distilled water to the rats and the intake of fluids was determined at 3, 6, 9, 12 and $24 \mathrm{~h}$ (on the first day) and on a daily basis thereafter, up to 3 days post-lesion ( $\mathrm{N}=10$ for SL-DRN and L-DRN rats).

Induced sodium appetite. Additionally, SL-DRN and L-DRN rats $(\mathrm{N}=11$ for both groups) were treated with a combination of furosemide (10 $\mathrm{mg} \mathrm{kg}^{-1} \mathrm{ml}^{-1}$, sc; Aventis Pharma, Suzano, SP, Brazil) + captopril (5 $\mathrm{mg} \mathrm{kg}{ }^{-1} \mathrm{ml}^{-1}$, sc; Aldrich). After $60 \mathrm{~min}$ without fluids or food, water and $0.3 \mathrm{M} \mathrm{NaCl}$ were made available in metabolic cages. Fluid

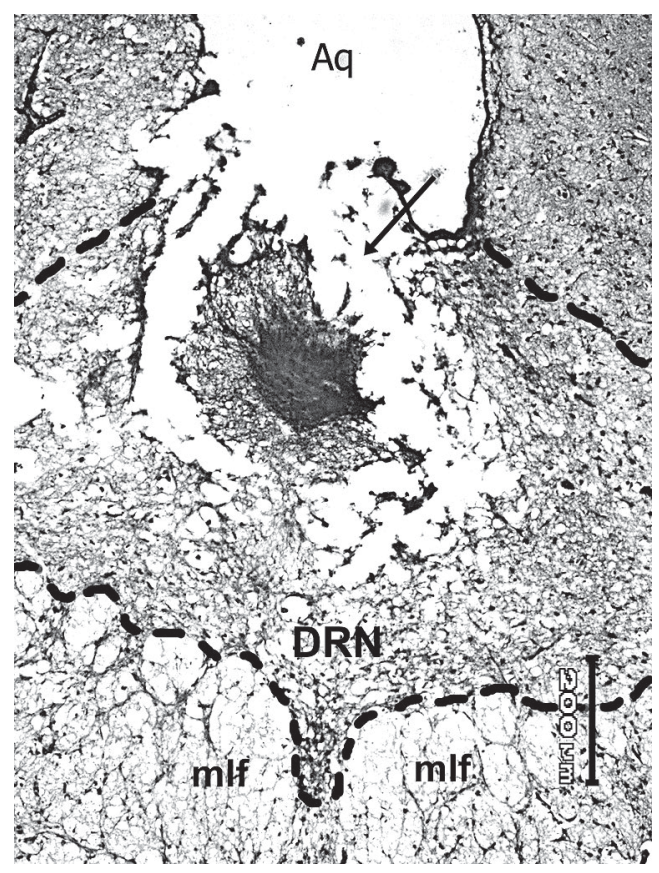

Figure 1. Photomicrograph of a histological section of the encephalon, at the level of the mesencephalon. The electrolytic lesion of the dorsal raphe nucleus (DRN, delimitated by the traced line) is indicated by the arrow. $\mathrm{Aq}=$ aqueduct, $\mathrm{mlf}=$ medial longitudinal fasciculus. Nissl, 5X. 
Figure 2. $A$, Water intake by dorsal raphe nucleus-lesioned (LDRN, filled squares) and shamlesioned (SL-DRN, open squares) rats deprived of water for $16 \mathrm{~h}$ $B$, Water intake by isoproterenol (ISO)- (L-DRN, filled circles; SLDRN, open circles) or isotonic saline- (L-DRN, filled triangles; SL-DRN, open triangles) treated rats. Data are reported as means \pm SEM. ${ }^{*} \mathrm{P}<0.0001$ compared to the SL-DRN group (panel A). $+P<0.05$ compared to the SLDRN group (panel B) (two-way ANOVA followed by the Newman-Keuls post-test). intake was determined over $2 \mathrm{~h}$ at 30-min intervals. In this situation, the effect of the ANG-converting enzyme inhibitor captopril increases plasma levels of ANG I available to the circumventricular organs of the lamina terminalis, probably the SFO, in which the local conversion to ANG II occurs, leading to the stimulation of water intake and of sodium appetite (4,23-25). Sodium preference was calculated according to the following formula: volume of $0.3 \mathrm{M} \mathrm{NaCl}$ intake/ volume of $0.3 \mathrm{M} \mathrm{NaCl}$ intake + volume of water intake.

\section{Results}

The electrolytic lesions of the DRN suitable for the investigation of ingestive responses extended from the dorsomedial to the ventromedial portion of the nucleus between the coordinates $\mathrm{AP}=7.6-8.4 \mathrm{~mm}$ and $\mathrm{V}=6.2-6.6 \mathrm{~mm}$ (Figure 1).

There was an increased sensitivity of LDRN rats to the dehydration induced by fluid deprivation with increased water in-
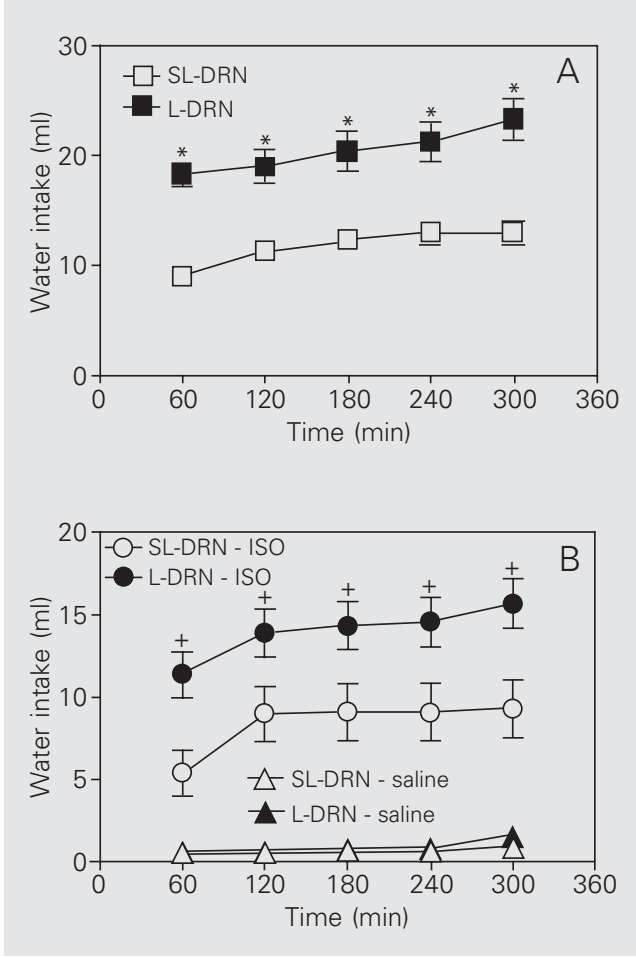

take throughout the period of observation (Figure 2A). After $5 \mathrm{~h}$ the cumulative water intake by L-DRN rats reached $23.3 \pm 1.9 \mathrm{ml}$ (a 79\% increase) while that of SL-DRN rats did not exceed $13.0 \pm 1.0 \mathrm{ml}(\mathrm{P}<0.0001)$. Similar results were observed in L-DRN rats treated with isoproterenol, in which the increase in water intake persisted throughout the experimental period (Figure 2B). After 5 $\mathrm{h}, \mathrm{L}-\mathrm{DRN}$ rats had ingested $15.7 \pm 1.47 \mathrm{ml}$ (a $69 \%$ increase, $\mathrm{P}<0.05)$ and SL-DRN rats, $9.3 \pm 1.8 \mathrm{ml}$.

L-DRN rats also exhibited an increased spontaneous sodium appetite throughout the period of assessment, while their water intake was higher than that by SL-DRN rats only during the first $12 \mathrm{~h}$ (Figure 3, panels A and B). The intake of $0.3 \mathrm{M} \mathrm{NaCl}$ after 12 , 24,36 and $72 \mathrm{~h}$ was $20.2 \pm 4.45,32.6 \pm 8.6$, $27.7 \pm 5.8$ and $26.9 \pm 4.7 \mathrm{ml}$ in L-DRN rats, and $0.97 \pm 0.31,3.3 \pm 1.1,4.2 \pm 1.3$ and 2.45 $\pm 0.86 \mathrm{ml}$ in SL-DRN rats, respectively $(\mathrm{P}<$ 0.00001 or less, at all time points). For comparative purposes, water and $0.3 \mathrm{M} \mathrm{NaCl}$ intake was measured cumulatively during the first $24 \mathrm{~h}$. Spontaneous sodium preference was significantly higher in L-DRN rats than in SL-DRN rats, ranging from $0.39 \pm$ $0.083 \mathrm{~h}$ post-lesion to $0.51 \pm 0.1224 \mathrm{~h}$ postlesion, maintaining a level 0.45 up to the 72 $\mathrm{h}$ of assessment $(\mathrm{P}<0.02$ or less, at all time points) (Figure 4 ).

The L-DRN rats submitted to sodium and water depletion, through the combined administration of furosemide + captopril, also exhibited an increased sodium appetite throughout the experiment compared to SLDRN ( $\mathrm{P}<0.02$ or less, at all time points) (Figure 5A). After $120 \mathrm{~min}$, the intake of 0.3 $\mathrm{M} \mathrm{NaCl}$ reached $13.9 \pm 2.0 \mathrm{ml}$, while among SL-DRN rats the intake was $4.6 \pm 0.64 \mathrm{ml}$. The differences in mean water intake between SL-DRN and L-DRN rats were not significant (Figure 5B). Sodium preference ranged from $0.51 \pm 0.045$ at $30 \mathrm{~min}$ to $0.52 \pm$ 0.047 at $120 \mathrm{~min}$ among depleted L-DRN rats, while it never exceeded $0.35 \pm 0.044$ (at 
120 min, $\mathrm{P}<0.002$, or less) among SL-DRN rats (Figure 6).

\section{Discussion}

The results of the present study reveal that electrolytic lesions of the DRN produced an increase in sensitivity to osmotic stimulation by dehydration induced by fluid deprivation and $\beta$-adrenergic stimulation with isoproterenol. This observation is consistent with the hypothesis that neurons of the DRN, which are probably serotonergic, exert a modulatory influence on the thirst related to an increase in the tonicity of extracellular fluid or on the thirst signaled by increased plasma levels of ANG II (4,19-21).

Neurons of the lamina terminalis (e.g., SFO, OVLT and MnPO) constitute the neuroanatomical substrate for the primary integration of thirst induced by osmotic stimulation and by $\beta$-adrenergic stimulation $(4,26$, 27). Serotonergic innervation originating in the mesencephalic raphe and receptors for serotonin have been identified throughout the lamina terminalis $(1,2,4-6,8)$.

The effects induced by DRN lesion suggest that ascending serotonergic pathways are involved in the modulation of the thirst induced by dehydration and brain angiotensinergic stimulation. The present observations support previous reports, which demonstrated that $i c v$ administration of the 5HT2C agonist, MK212, modulates water intake induced by fluid deprivation obtained by central microinjection of ANG II or carbachol as well as by central or systemic administration of the $\beta$-adrenergic agonist isoproterenol (14-16). More recently, these observations were extended through the use of other dipsogenic challenges in which the $i c v$ administration of a $5 \mathrm{HT} 2 \mathrm{~B} / 2 \mathrm{C}$ agonist, $\mathrm{mCPP}$, inhibited water intake induced by fluid deprivation, acute overload with hypertonic saline and hypovolemia (17).

Similarly, homeostatic integration of sodium appetite depends on structures in the lamina terminalis (4). The SFO and OVLT constitute convergent sites for signals related to volume depletion $(4,18,28,29)$. As mentioned previously, these structures are innervated by serotonergic neurons, are rich in serotonin receptors and reciprocally transmit signals to the raphe $(1,2,4-6,8)$. It is quite likely that these signals reflect adjustments concerning variations in volume, electrolytic composition of the extracellular fluid and cardiovascular parameters $(4,5,7,30)$.

Lesions of the DRN induced an increase in sodium appetite both under basal conditions and in the paradigm of sodium and
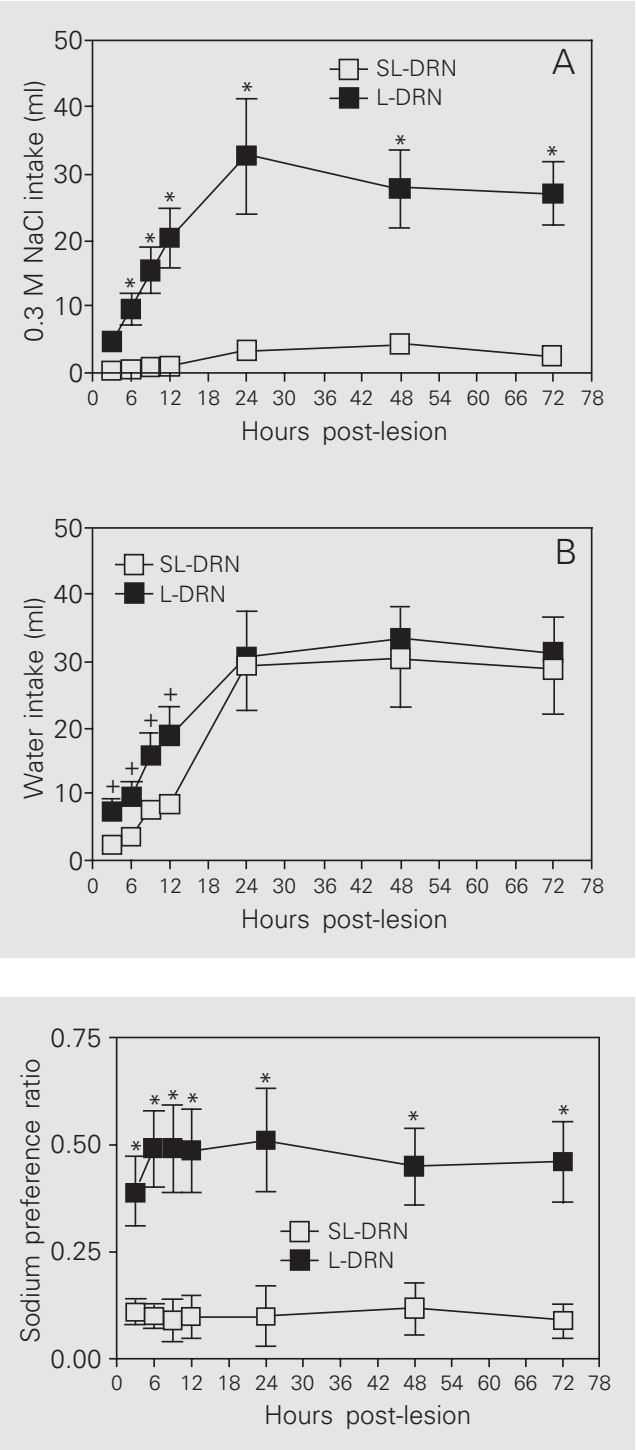

Figure 3. $A$, Intake of $0.3 \mathrm{M} \mathrm{NaCl}$ by dorsal raphe nucleus-lesioned (L-DRN, filled squares) and sham-lesioned rats (SLDRN, open squares) under basal conditions. $B$, Water intake of L-DRN (filled squares) and SLDRN (open squares) rats under basal conditions. Data are reported as means \pm SEM. ${ }^{*} \mathrm{P}<$ 0.00001 for $0.3 \mathrm{M} \mathrm{NaCl}$ intake and $+P<0.05$ for water intake, compared to the SL-DRN group (two-way ANOVA followed by the Newman-Keuls post-test).

Figure 4. Sodium preference of dorsal raphe nucleus-lesioned (L-DRN, filled squares) and sham-lesioned rats (SL-DRN, open squares) under basal conditions. Data are reported as means \pm SEM. ${ }^{*} P<0.02 \mathrm{com}-$ pared to the SL-DRN group (twoway ANOVA followed by the Newman-Keuls post-test). 
Figure 5. Intake of $0.3 \mathrm{M} \mathrm{NaCl}$ and water (panels $A$ and $B$, respectively) by dorsal raphe nucleus-lesioned (L-DRN, filled squares) and sham-lesioned rats (SL-DRN, open squares) submitted to sodium and water depletion induced by treatment with furosemide + captopril. Data are reported as means \pm SEM. ${ }^{*} \mathrm{P}<$ 0.02 for $0.3 \mathrm{M} \mathrm{NaCl}$ intake and $+\mathrm{P}<0.05$ for water intake compared to the SL-DRN group (twoway ANOVA followed by the Newman-Keuls post-test).
Figure 6. Sodium preference of dorsal raphe nucleus-lesioned ( $L$ DRN, filled squares) and shamlesioned rats (SL-DRN, open squares) submitted to sodium and water depletion induced by treatment with furosemide + captopril. Data are reported as means \pm SEM. ${ }^{*} P<0.002 \mathrm{com}-$ pared to the SL-DRN group (twoway ANOVA followed by the Newman-Keuls post-test). water depletion provoked by combined administration of furosemide and a low dose of captopril. These data show that under basal conditions without a natriorexigenic challenge, electrolytic lesion of the DRN promotes the suppression of a tonic modulatory pathway of sodium appetite. Recent evidence has shown that sodium depletion induced by the combination of furosemide with a low dose of captopril causes an increase in c-Fos expression in the nucleus tractus solitarii (NTS), which is suppressed by renal deafferentation (31). Following the same line of reasoning, evoked potentials were recorded in serotonergic neurons of the DRN after the
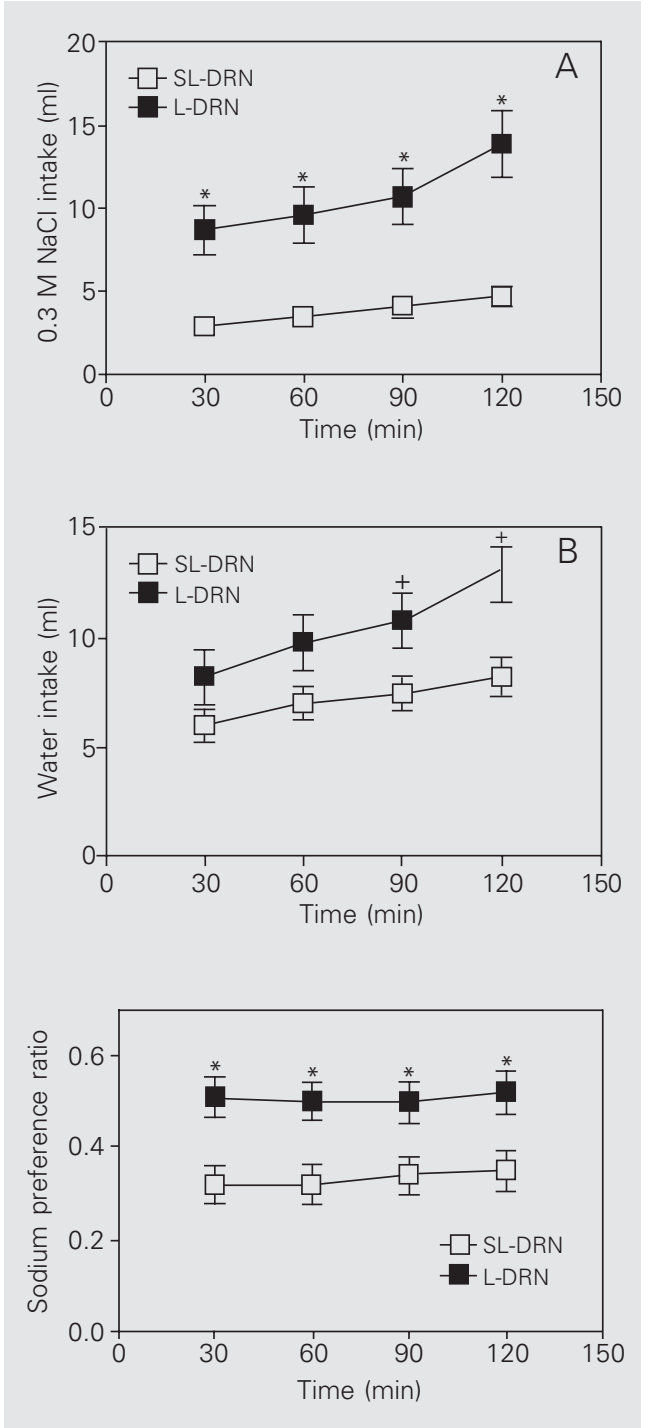

isoosmotic loss of volume by hemorrhage and, more specifically, induction of c-Fos expression was determined in serotonergic neurons of the DRN and in structures of the lamina terminalis after sodium depletion by peritoneal dialysis $(7,18)$.

These observations permit us to propose that moment-to-moment adjustments of renal sodium load and extracellular fluid volume generate signals that are transmitted to the NTS and, from there, to the DRN. Alternatively, other pertinent observations support the hypothesis that volume depletion (and possibly the serial changes in arterial pressure) activates neurons of the SFO sensitive to ANG II, which project to form synapses with serotonergic neurons of the DRN $(7,30)$. As a result of this monitoring of the circulating levels of ANG II, signals would be generated and transmitted by ascending serotonergic pathways of the DRN with the objective of modulating sodium appetite, with subsequent regulation of extracellular fluid volume. According to this hypothesis, the removal of a tonic modulatory pathway would imply a greater sensitivity/activity of angiotensinergic mechanisms in the lamina terminalis implicated in the central control of dipsogenesis and of sodium appetite.

Another hypothesis is based on the widely accepted concept that ANP is involved in the modulation of thirst induced by dehydration or by central angiotensinergic stimulation, and of sodium appetite provoked by sodium depletion $(32,33)$. This same group showed that lesions of the wall of the AV $3 \mathrm{~V}$ region drastically reduce the plasma levels of ANP, mediating the expansion of blood volume (34). Taken together, these observations lead to the conclusion that structures in the lamina terminalis constitute the substrate which integrates signals designed to regulate the release of ANP. In view of the observations cited above, regarding the neural interactions between structures of the lamina terminalis and mesencephalic raphe, we suggest 
that electrolytic lesions of the DRN remove an excitatory serotonergic component involved in the release of ANP and, thus causing dysfunction of the system responsible for adjustments in volume and the maintenance of homeostasis, with a subsequent increase in sodium preference $(3,35)$.

The oxytocin produced by the paraventricular nucleus is a candidate for a central mediator of satiety for sodium (4,36-38). Alternatively, this may constitute another modulatory pathway for sodium appetite dependent on serotonergic ascending activation, since serotonergic innervation of the paraventricular nucleus has been well established $(1,2,8,39)$. In addition, an increase in Fos immunoreactivity was shown in oxytocinergic neurons during the process of sodium satiety in rats previously depleted of sodium by peritoneal dialysis (37).

These conclusions are consistent with the current literature. The existence of re- dundancy of multiple effector reactions concerned with the process of sodium satiety might be explained by the insertion of serotonergic circuits in a polymodal system of recruitment/homeostatic activation at different levels of physiological disturbances of tonicity and extracellular fluid volume. In view of the hypotheses presented, the results obtained are compatible with the assumption that electrolytic lesion of the DRN suppresses a tonic inhibitory component of sodium appetite.

\section{Acknowledgments}

The authors are grateful to Dr. Karla Consort Ribeiro, Laboratório de Cardiologia Celular e Molecular, Instituto de Biofísica Carlos Chagas Filho, Universidade Federal do Rio de Janeiro, for preparing the photomicrographs, and to Dr. Wellington da Silva Côrtes for help with the English text.

\section{References}

1. Azmitia EC \& Segal M (1978). An autoradiographic analysis of the differential ascending projections of the dorsal and median raphe nuclei in the rat. Journal of Comparative Neurology, 179: 641-668.

2. Steinbusch HWM (1981). Distribution of serotonin-immunoreactivity in the central nervous system of the rat cell bodies and terminals. Neuroscience, 6: 557-618.

3. Reis LC, Ramalho MJ, Favaretto AL, Gutkowska J, McCann SM \& Antunes-Rodrigues J (1994). Participation of the ascending serotonergic system in the stimulation of atrial natriuretic peptide release. Proceedings of the National Academy of Sciences, USA, 91: 1202212026.

4. Fitzsimons JT (1998). Angiotensin, thirst, and sodium appetite. Physiological Reviews, 78: 583-686

5. Lind RW (1986). Bi-directional, chemically specified neural connections between the subfornical organ and the midbrain raphe system. Brain Research, 384: 250-261.

6. Bosler O \& Descarries L (1988). Monoamine innervation of the organum vasculosum laminae terminalis (OVLT): a high resolution radioautographic study in the rat. Journal of Comparative Neurology, 272: 545-561.

7. Tanaka J, Okumura T, Sakamati K \& Miyakubo H (2001). Activation of serotonergic pathways from the midbrain raphe system to the subfornical organ by hemorrhage in the rat. Experimental Neurology, 169: 156-162.

8. Scrogin KE, Johnson AK \& Schmid HA (1998). Multiple receptor subtypes mediate the effects of serotonin on rat subfornical organ neurons. American Journal of Physiology, 275: R2035-R2042.
9. Bealer SL (1988). Acute hypertensive and natriuretic responses following preoptic hypothalamic lesions. American Journal of the Medical Sciences, 295: 346-351.

10. De Luca Jr LA \& Menani JV (1996). Preoptic-periventricular tissue (AV3V): central cholinergic-induced hydromineral and cardiovascular responses, and salt intake. Revista Brasileira de Biologia, 56 (Suppl 1): 233-238.

11. De Luca Jr LA, Sugawara AM \& Menani JV (2000). Brain versus peripheral angiotensin II receptors in hypovolemia: behavioural and cardiovascular implications. Clinical and Experimental Pharmacology and Physiology, 27: 437-442.

12. Stein JM, Lind RW \& Johnson AK (1987). Central serotonergic influences on renal electrolyte and water excretion. Neuropharmacology, 26: 1685-1692.

13. Reis LC, Ramalho MJ \& Antunes-Rodrigues J (1991). Effect of central administration of serotoninergic agonists on electrolyte excretion control. Brazilian Journal of Medical and Biological Research, 24: 633-641.

14. Reis LC, Ramalho MJ \& Antunes-Rodrigues J (1990). Central serotonergic modulation of drinking behavior induced by water deprivation. Effect of serotonergic agonist (MK-212) administered intracerebroventricularly. Brazilian Journal of Medical and Biological Research, 23: 1335-1338.

15. Reis LC, Ramalho MJ \& Antunes-Rodrigues J (1990). Central serotonergic modulation of drinking behavior induced by angiotensin II and carbachol in normally hydrated rats. Effect of intracerebroventricular injection of MK-212. Brazilian Journal of Medical and Biologi- 
cal Research, 23: 1339-1342.

16. Reis LC, Ramalho MJ \& Antunes-Rodrigues J (1992). Brain serotoninergic stimulation reduces the water intake induced by systemic and central beta-adrenergic administration. Brazilian Journal of Medical and Biological Research, 25: 529-536.

17. Castro L, Maldonado I, Campos I, Varjão B, Angelo AL, Athanazio RA, Barbetta MC, Ramos AC, Fregoneze JB \& De Castro e Silva $E$ (2002). Central administration of mCPP, a serotonin $5-\mathrm{HT}(2 \mathrm{~B} / 2 \mathrm{C})$ agonist, decreases water intake in rats. Pharmacology, Biochemistry and Behavior, 72: 891-898.

18. Franchini LF, Johnson AK \& Vivas L (2002). Sodium appetite and Fos activation in serotonergic neurons. American Journal of Physiology, 282: R235-R243.

19. Phillips MI, Hoffman WE \& Bealer SL (1982). Dehydration and fluid balance: central effects of angiotensin. Federation Proceedings, 41: 2520-2527.

20. Lind RW, Thunhorst RL \& Johnson AK (1984). The subfornical organ and the integration of multiple factors in thirst. Physiology and Behavior, 32: 69-74

21. Ramsay DJ \& Thrasher TN (1986). Hyperosmotic and hypovolemic thirst. In: de Caro G, Epstein AN \& Massi M (Editors), The Physiology of Thirst and Sodium Appetite. Plenum Press, New York, 83-96.

22. Paxinos G \& Watson C (1986). The Rat Brain in Stereotaxic Coordinates. 2nd edn. Academic Press, New York.

23. Fitts DA \& Masson DB (1989). Forebrain sites of action for drinking and salt appetite to angiotensin or captopril. Behavioral Neuroscience, 103: 865-872.

24. Menani JV, Thunhorst RL \& Johnson AK (1996). Lateral parabrachial nucleus and serotonergic mechanisms in the control of salt appetite in rats. American Journal of Physiology, 270: R162-R168.

25. Rauch M \& Schmid HA (1999). Functional evidence for subfornical organ intrinsic conversion of angiotensin I to angiotensin II. American Journal of Physiology, 276: R1630-R1638.

26. Thrasher TN \& Keil LC (1987). Regulation of drinking and vasopressin secretion: role of organum vasculosum laminae terminalis. American Journal of Physiology, 253: R108-R120.

27. Fitts DA (1994). Angiotensin II receptors in SFO but not in OVLT mediate isoproterenol-induced thirst. American Journal of Physiology, 267: R7-R15.

28. Vivas L, Pastuskovas CV \& Tonelli L (1995). Sodium depletion induces Fos immunoreactivity in circumventricular organs of the lamina terminalis. Brain Research, 679: 34-41.

29. Pastuskovas C \& Vivas $L$ (1997). Effect of intravenous captopril on c-fos expression induced by sodium depletion in neurons of the lamina terminalis. Brain Research Bulletin, 44: 233-236.

30. Tanaka J, Ushigome A, Hori K \& Nomura M (1998). Response of raphe nucleus projecting subfornical organ neurons to angiotensin II in rats. Brain Research Bulletin, 45: 315-318.

31. Fitch GK \& Weiss ML (2000). Activation of renal afferent pathways following furosemide treatment. II. Effect of angiotensin blockade. Brain Research, 861: 377-389.

32. Antunes-Rodrigues J, McCann SM \& Samsom WK (1985). Atrial natriuretic factor inhibits dehydration- and angiotensin II-induced water intake in the conscious, unrestrained rat. Proceedings of the National Academy of Sciences, USA, 82: 8720-8723.

33. Antunes-Rodrigues J, McCann SM, Rogers LC \& Samsom WK (1986). Central administration of atrial natriuretic factor inhibits saline preference in the rat. Endocrinology, 118: 1726-1728.

34. Antunes-Rodrigues J, Ramalho MJ, Reis LC, Menani JV, Turrin MO, Gutkowska J \& McCann SM (1991). Lesions of the hypothalamus and pituitary inhibit volume-expansion-induced release of atrial natriuretic peptide. Proceedings of the National Academy of Sciences, USA, 88: 2956-2960.

35. Reis LC (1993). Participação do sistema serotoninérgico central na regulação do equilíbrio hidroeletrolítico. Doctoral thesis, Faculty of Medicine of Ribeirão Preto, São Paulo University, Ribeirão Preto, SP, Brazil.

36. Johnson AK \& Thunhorst RL (1997). The neuroendocrinology of thirst and salt appetite: visceral sensory signals and mechanisms of central integration. Frontiers in Neuroendocrinology, 18: 292-353.

37. Franchini LF \& Vivas L (1999). Distribution of Fos immunoreactivity in rat brain after sodium consumption induced by peritoneal dialysis. American Journal of Physiology, 276: R1180-R1187.

38. Amico JA, Morris M \& Vollmer RR (2001). Mice deficient in oxytocin manifest increased saline consumption following overnight fluid deprivation. American Journal of Physiology, 281: R1368-R1373.

39. Van de Kar LD, Rittenhouse PA, Li Q, Levy AD \& Brownfield MS (1995). Hypothalamic paraventricular, but not supraoptic neurons, mediate the serotonergic stimulation of oxytocin secretion. Brain Research Bulletin, 36: 45-50. 